\title{
Ex Vivo Area-Metric Analysis of Root Canal Obturation Using Cold and Warm Gutta-Percha
}

\author{
Katarzyna Olczak, ${ }^{1}$ Leszek Klimek, ${ }^{2}$ and Halina Pawlicka ${ }^{1}$ \\ ${ }^{1}$ Department of Endodontics, Medical University of Lodz, Poland, Pomorska 251, 92-213 Lodz, Poland \\ ${ }^{2}$ Department of Materials Science and Engineering, Lodz University of Technology, Poland Stefana Żeromskiego 116, \\ 90-924 Lodz, Poland
}

Correspondence should be addressed to Katarzyna Olczak; kolczak@op.pl

Received 6 May 2016; Accepted 9 October 2016

Academic Editor: Ying Li

Copyright (C) 2016 Katarzyna Olczak et al. This is an open access article distributed under the Creative Commons Attribution License, which permits unrestricted use, distribution, and reproduction in any medium, provided the original work is properly cited.

Purpose. To evaluate the percentage content of gutta-percha, sealer, and voids in a filled canal area following three different filling techniques, using microphotographs and Nis Elements ${ }^{\circledR}$ software. Material and Methods. After completing chemomechanical preparation, the teeth $(n=48)$ were randomly divided into three groups $(n=16)$ and filled by either cold lateral condensation (CLC group), the continuous wave technique (EOU group), and the ProTaper ${ }^{\circledR}$ thermoplasticized obturator (PT group). The roots were then sectioned horizontally $2.5,6.5$ and $8.5 \mathrm{~mm}$ from the tooth apical foramen. The surface areas of the sealer, voids, and guttapercha (PGFA percentage of gutta-percha-filled area) were calculated and the results subjected to statistical analysis (Kruskal-Wallis test). Results. The percentage of gutta-percha (PGFA) was lower in the apical third of the canal for the CLC and EOU groups than the PT group. In the middle and the coronal third of the canal, the PGFA value was higher after using thermal techniques (EOU and PT) than cold lateral condensation (CLC). The presence of voids was comparable in the fillings performed using warm and cold gutta-percha obturation at all levels. Conclusion. Although thermal methods of root canal obturation allow higher PGFA values to be obtained than cold lateral condensation, the content of voids is comparable.

\section{Introduction}

An adequately cleaned and shaped root canal system has to be properly filled. The success or failure of endodontic treatment depends to a great extent on tight homogeneous obturation of the pulp cavity [1]. It has been shown that, in many cases, irrespective of the applied root canal widening technique or instrumentarium, some portions of canals are not available to chemomechanical procedures and remain unprepared $[2,3]$. Thus, proper filling of the root canal system is one of the most important stages of endodontic treatment and significantly affects its final outcome.

Over the last two hundred years, nearly a hundred techniques and five hundred materials have been used to obturate the pulp cavity. Nowadays, root canals are mainly filled with gutta-percha combined with a small amount of sealer, using cold or warm gutta-percha methods [1]. Whichever method of canal obturation is chosen, endodontists strive to create a canal filling containing $90 \%$ gutta-percha. The amount of sealer should be minimized, as it is subject to shrinkage and solubility, which are incompatible with longterm sealing. If dissolution occurs, either at the interface between gutta-percha and the dentin wall or between the gutta-percha points themselves, leakage may occur within the space originally taken up by the sealer [4].

Numerous reports emphasize that thermal methods of root canal filling allow endodontists to achieve a more advantageous ratio of gutta-percha to sealer than cold guttapercha techniques [5-7]. However, some publications present quite different outcomes $[8,9]$. There is no consensus in the literature as regards the amount of voids in canals filled with various methods, and the superiority of one method over the other methods cannot be established [10, 11]. Hence, the aim of this present study is to compare warm and cold gutta-percha techniques to determine how they influence the quality of root canal filling, by evaluating the percentage of 
gutta-percha, sealer, and voids in the filled canal area following the application of three different root canal obturation techniques.

\section{Materials and Methods}

The experiment was approved by the Bioethics Committee of the Medical University of Lodz (number RNN/129/08/KE). Forty-eight roots of extracted human maxillary anterior teeth were used in the study. The teeth were randomly assigned to three groups of 16 teeth. The criteria for selecting the roots for the study were as follows: no previous root canal treatment; no visible signs of root damage in the form of caries, resorption, or root fracture; fully developed root apices present; only one round, straight root canal present. Prior to canal instrumentation, the roots were shortened to the same working length $(11.5 \mathrm{~mm})$. The root canals were chemomechanically prepared with ProTaper engine-driven rotary instruments (Dentsply Maillefer ${ }^{\circledR}$, Ballaigues, Switzerland) to a final size of F3. After chemomechanical preparation, the canals were dried and filled as follows.

2.1. Group 1: Cold Lateral Condensation (CLC Group). Standard gutta-percha cones (Dentsply Maillefer, Ballaigues, Switzerland) were fitted to working length and exhibited a "tug back" sensation during their removal from the canal. The canal walls were covered with a thin layer of sealer (AH Plus sealer ${ }^{\circledR}$, Dentsply Maillefer, Ballaigues, Switzerland) using a paper point (Dentsply Maillefer, Ballaigues, Switzerland). The master cone was coated with a small amount of sealer and inserted to the full working length. Lateral compaction was performed using a size 25 nickel-titanium spreader and size 20 accessory gutta-percha cones (Dentsply Maillefer, Ballaigues, Switzerland). After removing the excess cones with a heated excavator, the filling was compacted vertically using a small ball plugger (Dentsply Maillefer, Ballaigues, Switzerland).

2.2. Group 2: Continuous Wave Technique Using Elements Obturation Units ${ }^{\circledR}$ (EOU Group). For the first stage of root canal preparation, warm vertical compaction of gutta-percha was performed using a size F3 ProTaper gutta-percha cone (Dentsply Maillefer, Ballaigues, Switzerland). Next, the canal walls were coated with a thin layer of sealer (AH Plus sealer, Dentsply Maillefer, Ballaigues, Switzerland) using a paper point (Dentsply Maillefer, Ballaigues, Switzerland). System B plugger, size FM (Elements Obturation Unit, SybronEndo, Glendora, USA), and a cold S-Kondenser ${ }^{\circledR}$ (SybronEndo, Glendora, USA) were applied for warm vertical compaction. The heated plugger was inserted into the canal to a depth $3 \mathrm{~mm}$ shorter than the determined working length. The heated plugger with a rubber stop was placed in the canal and condensation was finished within $3 \mathrm{~mm}$ of the predetermined working length, to fill the apical $3 \mathrm{~mm}$ portion of the canal. At the second stage of canal preparation, the middle and coronal portions of the canal were obturated by injecting warm guttapercha delivered from the Extruder of Elements Obturation Unit. Each portion of gutta-percha was condensed vertically with S-Kondenser. The procedure of warm gutta-percha injection and condensation was repeated twice until the gutta-percha reached the coronal orifice of the canal.

2.3. Group 3: ProTaper Thermoplasticized Obturator (PT Group). ProTaper obturators \#F3 (Dentsply Maillefer, Ballaigues, Switzerland) were used to fill the root canals of the PT group. The root canal walls were covered with a thin layer of sealer (AH Plus sealer, Dentsply Maillefer, Ballaigues, Switzerland) according to the manufacturer's recommendations. Next, the F3 obturator was placed in the ThermaPrep Plus ${ }^{\circledR}$ oven (Dentsply Maillefer, Ballaigues, Switzerland) to heat the gutta-percha. After inserting a carrier in the canal to the previously determined working length, a constant, light apical pressure was exerted for $10 \mathrm{~s}$ to prevent the withdrawal of the carrier from the canal. A bur (Therma-Cut, Dentsply Maillefer, Ballaigues, Switzerland) was used to remove the obturator tip without water cooling, and the extending guttapercha was vertically condensed with a plugger (Dentsply Maillefer, Ballaigues, Switzerland).

Teeth were stored at $37^{\circ} \mathrm{C}$ and $100 \%$ humidity for 3 weeks. Each tooth was mounted in a low speed saw and each root was horizontally sectioned $2.5 \mathrm{~mm}$ (section A), $6.5 \mathrm{~mm}$ (section B), and $8.5 \mathrm{~mm}$ (section C) from the tooth apical foramen (Figures 1-3). The specimens were pushed towards the rotating saw disk using light pressure, with the teeth being constantly refreshed with water. This saw proved effective in preventing the gutta-percha from smearing. The sections were viewed under a metallographic microscope (Nikon Eclipse MA 200) at 50x magnification and photographed using a digital system mounted on the metallographic microscope. Nis Elements software was used to calculate the surface areas of the gutta-percha, sealer, and voids. The areas of the canal and gutta-percha, sealer, or voids were manually outlined and then measured. The areas representing guttapercha, sealer, or voids were expressed as percentages of total canal area. The results were subjected to statistical analysis using Statistica 10 software and the nonparametric KruskalWallis test $(p<0.05)$.

\section{Results}

3.1. Gutta-Percha-Filled and Sealer-Filled Canal Areas. In the apical third of the canal (section A), the percentages of the canal filled by gutta-percha and sealer resulting from the cold lateral condensation and the continuous wave methods were comparable. The PGFA values for the CLC group were lower than for the EOU group, but the difference was not statistically significant. In the apical third of the canal, the thermoplasticized obturator technique resulted in a significantly higher percentage of gutta-percha than the other groups (Figures 4 and 7). In the middle and the coronal third of the canal (sections B and C), the percentage of gutta-percha in the filled canal area was considerably higher after using thermal techniques than cold lateral condensation (Figures 5 and 6). In sections $\mathrm{B}$ and $\mathrm{C}$, no significant differences were found between the thermoplasticized techniques: all had a significantly higher gutta-percha distribution than cold lateral condensation (Figures 8 and 9). 


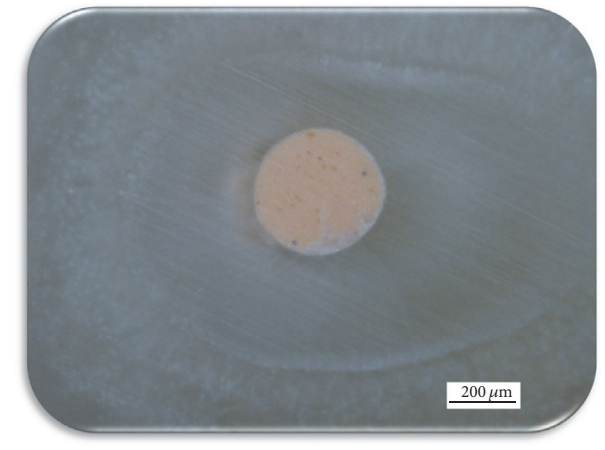

FIGURE 1: A representative cross section of a root canal filling using the cold lateral condensation technique (CLC Group), section A.

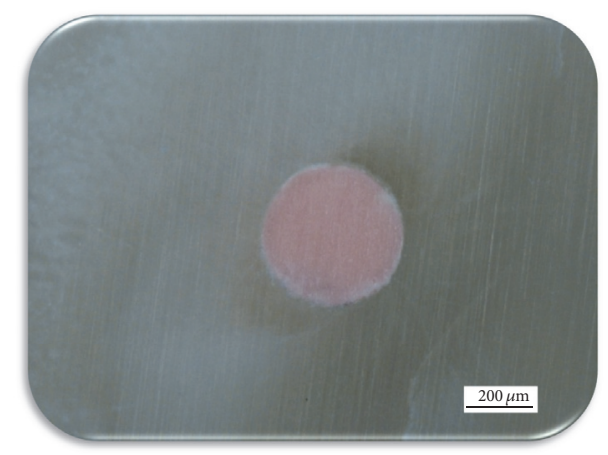

Figure 2: A representative cross section of a root canal filling using the continuous wave technique and Elements Obturation Units (EOU Group), section A.

3.2. The Proportion of Void in the Filled Canal Area. At all levels examined, the area occupied by voids was very small after all root canal filling techniques (Figures 4-6), and no significant differences were found between cold and warm gutta-percha methods regarding the amount of voids. Although the percentage of void filled canal areas was slightly higher in the CLC group than the EOU and PT groups, the difference was not statistically significant (Figures 10-12).

\section{Discussion}

4.1. Gutta-Percha-Filled and Sealer-Filled Canal Areas. No statistically significant differences were found between the cold lateral condensation and the continuous wave technique regarding the amounts of gutta-percha and sealer in fillings. Other authors indicate a comparable amount of guttapercha in canals filled by cold lateral and warm vertical compaction [6, 8, 9]. De-Deus et al. [8] and Gençoglu et al. [9] report the mean amounts of gutta-percha on longitudinal cross sections $2 \mathrm{~mm}$ from the apex to be $82.6 \%$ after cold lateral condensation and $80.5-85.6 \%$ after warm vertical compaction (System $\mathrm{B}^{\circledR}$ ). Similarly, Wu et al. [6] do not report any statistically significant difference between cold lateral condensation and injection methods with regard to PGFA in cross sections of mandibular incisors $2 \mathrm{~mm}$ from the

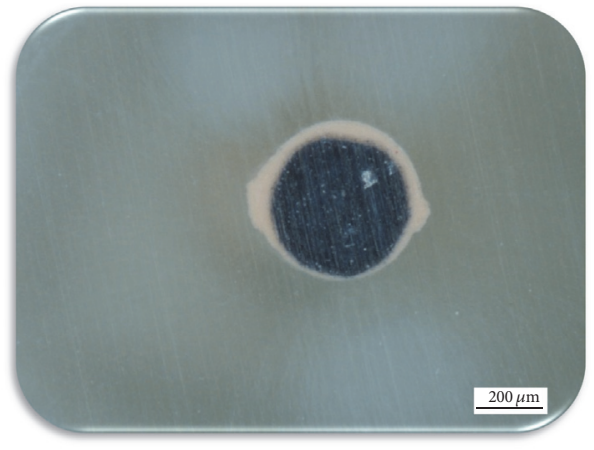

FIGURE 3: A representative cross section of a root canal filling using the ProTaper thermoplasticized obturator (PT Group), section A.

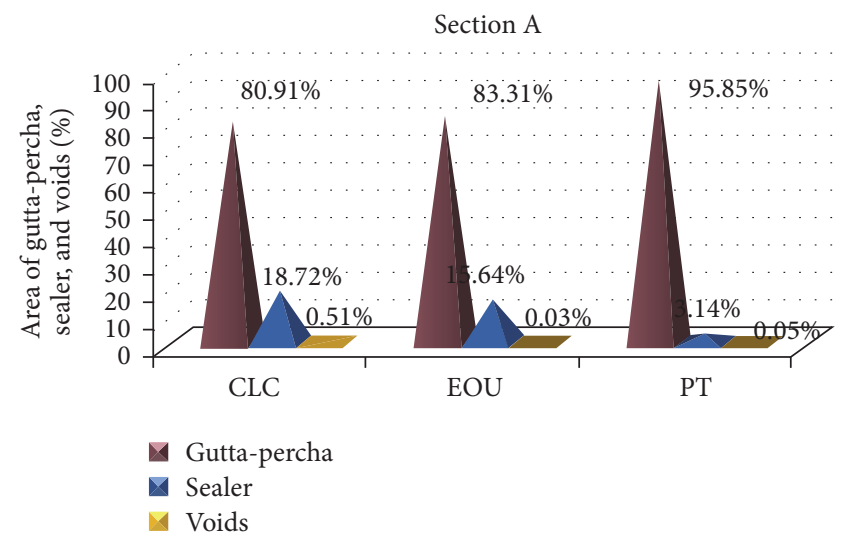

FIGURE 4: The percentage of the canal area filled with gutta-percha, sealer, and voids after using three gutta-percha techniques, section A.

apex. In both methods, over $90 \%$ of the root canal content was occupied by gutta-percha. In the present study, such high gutta-percha content was observed only in canals filled with the thermoplasticized obturator. Other researchers also report the PGFA index in the apical third of canals to be higher in those filled with Thermafil ${ }^{\circledR}$ than by cold lateral or warm vertical gutta-percha compaction [12-14]. High PGFA values were associated with the thermoplasticized obturator method at all examined levels in the fillings. Starting from the cross section located at $6.5 \mathrm{~mm}$ from the anatomical foramen, no statistically significant difference was detected in the percentages of gutta-percha- and sealer-filled areas between the canals filled with the continuous wave of compaction and those obturated with the thermoplasticized obturator. In the middle and coronal part of the canal, both methods presented distinctly higher PGFA values than cold lateral condensation. Similar results are given in other publications. $\mathrm{Wu}$ et al. [6] report a significantly greater higher PGFA value in canals obturated with combined warm vertical compaction and injection (Touch'n Heat ${ }^{\circledR}+$ Ultrafil $^{\circledR}$ ) than canals filled with cold lateral condensation at $4 \mathrm{~mm}$ from the apex: $99.6 \%$ after using the thermal method and $94.1 \%$ after cold lateral condensation. In another study, canals filled with the continuous wave and Thermafil techniques were found 


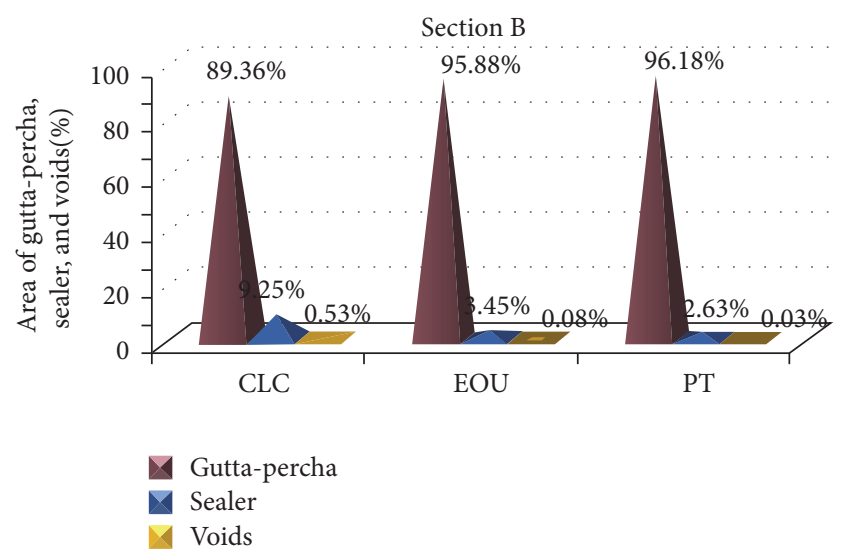

FIGURE 5: The percentage of the canal area filled with gutta-percha, sealer, and voids after using three gutta-percha techniques, section B.

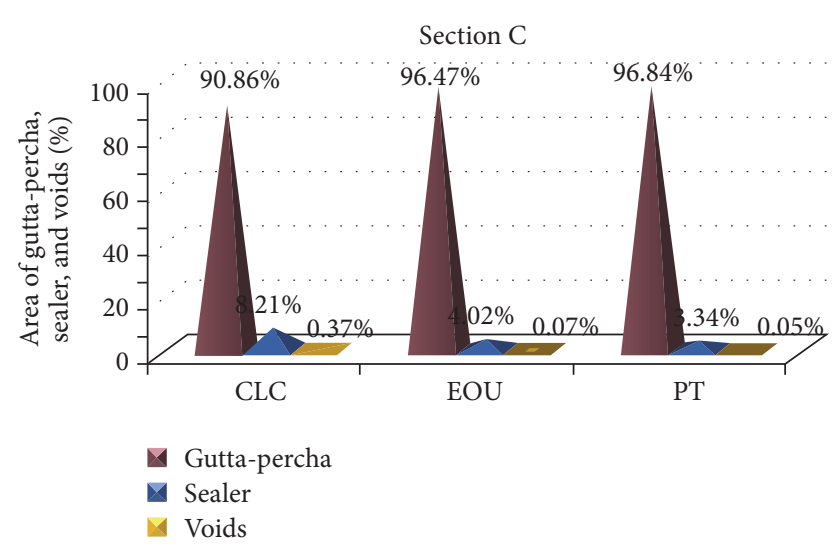

Figure 6: The percentage of the canal area filled with gutta-percha, sealer, and voids after using three gutta-percha techniques, section C.

to demonstrate significantly higher PGFA values $5 \mathrm{~mm}$ from the apex than those filled by lateral condensation of cold gutta-percha [7]. A third study taken at the middle of the root length, $6 \mathrm{~mm}$ from the apex, revealed a higher PGFA index in the canals obturated with combined warm vertical compaction and injection (96.2\%) than those obturated with cold lateral condensation (90.1\%) [7]. Cathro and Love [15], based on an examination of 10 root cross sections taken $1-10 \mathrm{~mm}$ from the anatomical foramen, report almost $100 \%$ gutta-percha content throughout a filling created by a combined System B + Obtura $\mathrm{II}^{\circledR}$ technique. Gulsahi et al. [16] found significantly higher gutta-percha content in fillings obturated with the thermoplasticized obturator than by cold lateral condensation of gutta-percha. In addition, a more advantageous gutta-percha/seal ratio was observed in canals prepared with the $\mathrm{GT}^{\circledR}$ rotary instrument system and filled with thermoplasticized GT obturators than in those made by Profile ${ }^{\circledR}$ files and obturated with Thermafil. This is likely to be associated with the better fit of the GT obturator to the shape and size of the canal prepared with the GT files. Hence, filling the canals with thermal methods allows a more

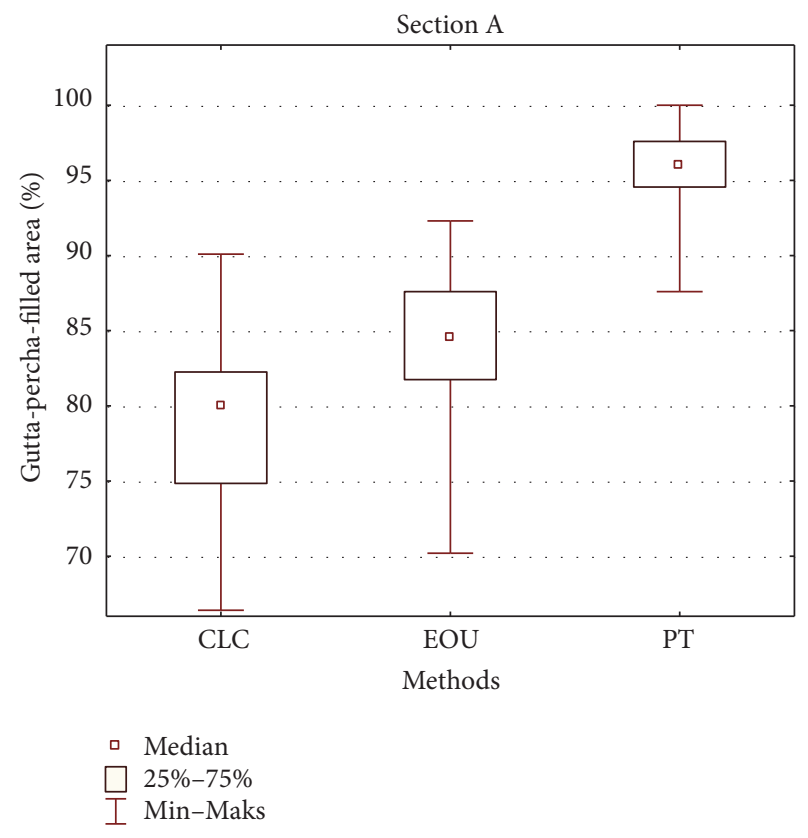

FIGURE 7: Box plots illustrating the median traces and minimal and maximal values of the gutta-percha-filled area in each experimental group, section $\mathrm{A}$.

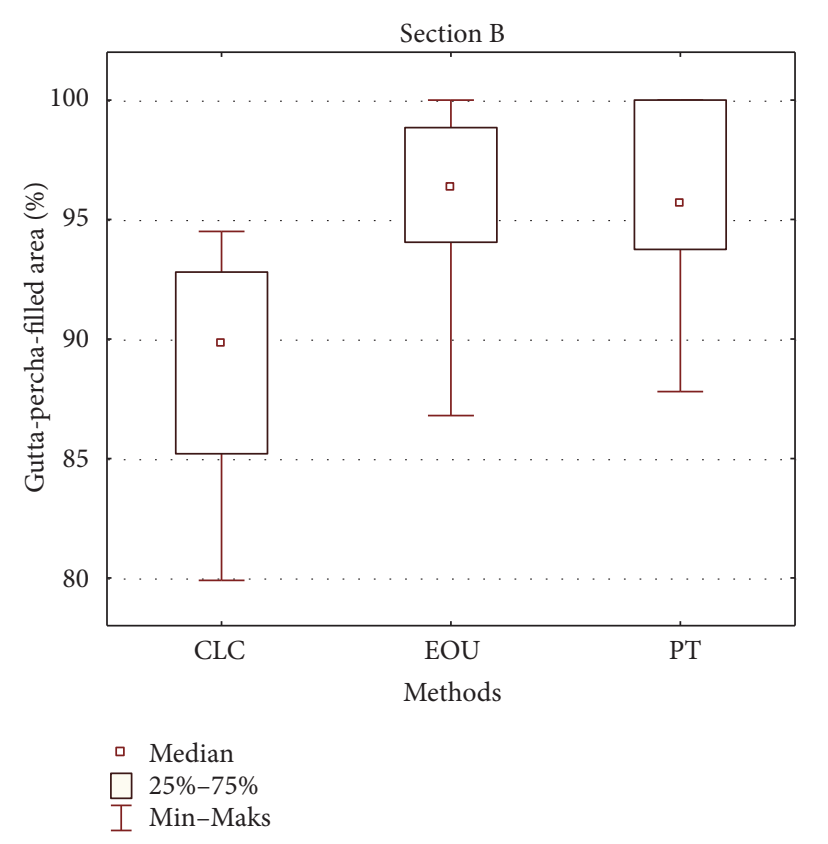

FIgURE 8: Box plots illustrating the median traces and minimal and maximal values of the gutta-percha-filled area in each experimental group, section $\mathrm{B}$.

favorable gutta-percha/sealer ratio to be obtained than by using the cold lateral condensation method. Similar statistical relationships are also presented by other authors, although the percentage distributions of gutta-percha, sealer, and voids in filled canals are not always comparable, due to the range of 


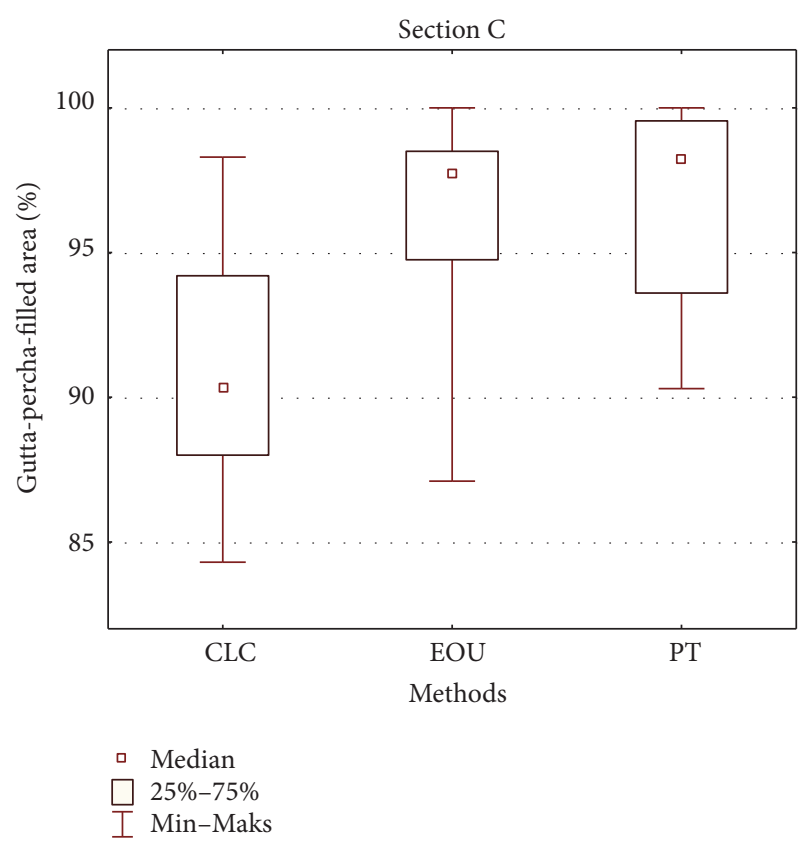

Figure 9: Box plots illustrating the median traces and minimal and maximal values of the gutta-percha-filled area in each experimental group, section C.

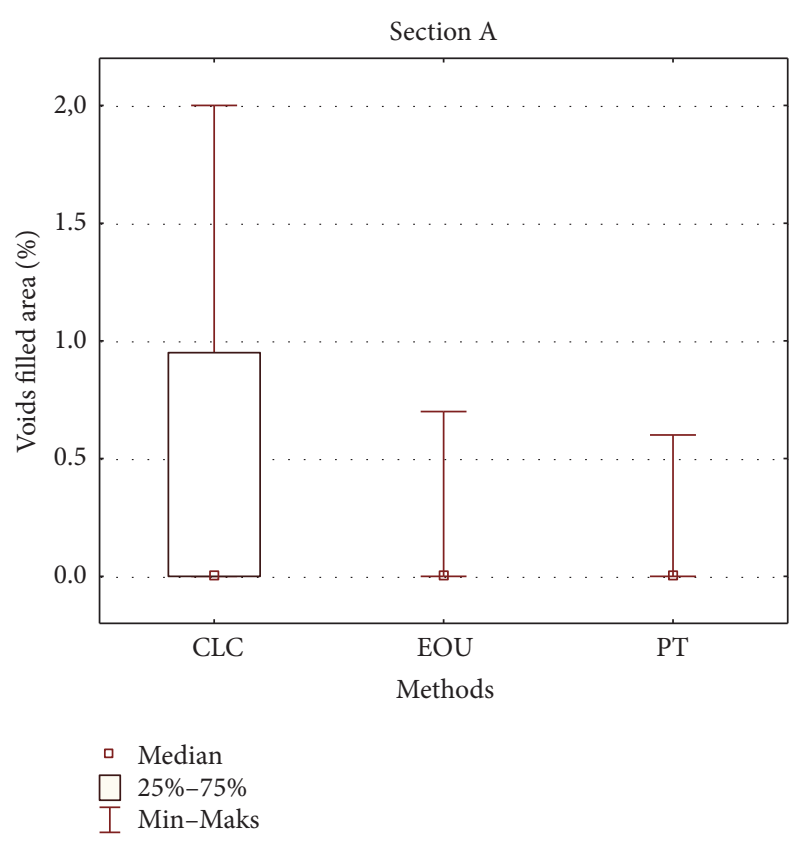

FIGURE 10: Box plots illustrating the median traces and minimal and maximal values of the voids in the filled area in each experimental group, section A.

root canal morphologies (oval or round, straight or curved canals) and modifications of pulp cavity obturation methods.

4.2. The Voids of the Filled Canal Area. The presence or absence of voids is a very important issue associated with the assessment of canal filling quality. Due to the physical and

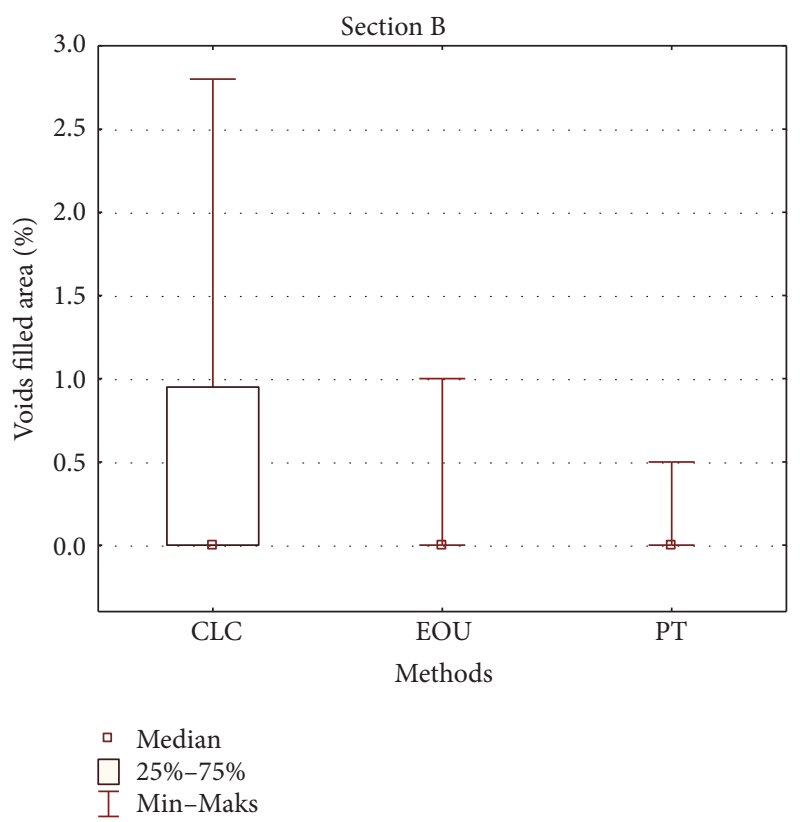

FIGURE 11: Box plots illustrating the median traces and minimal and maximal values of the voids in the filled area in each experimental group, section $\mathrm{B}$.

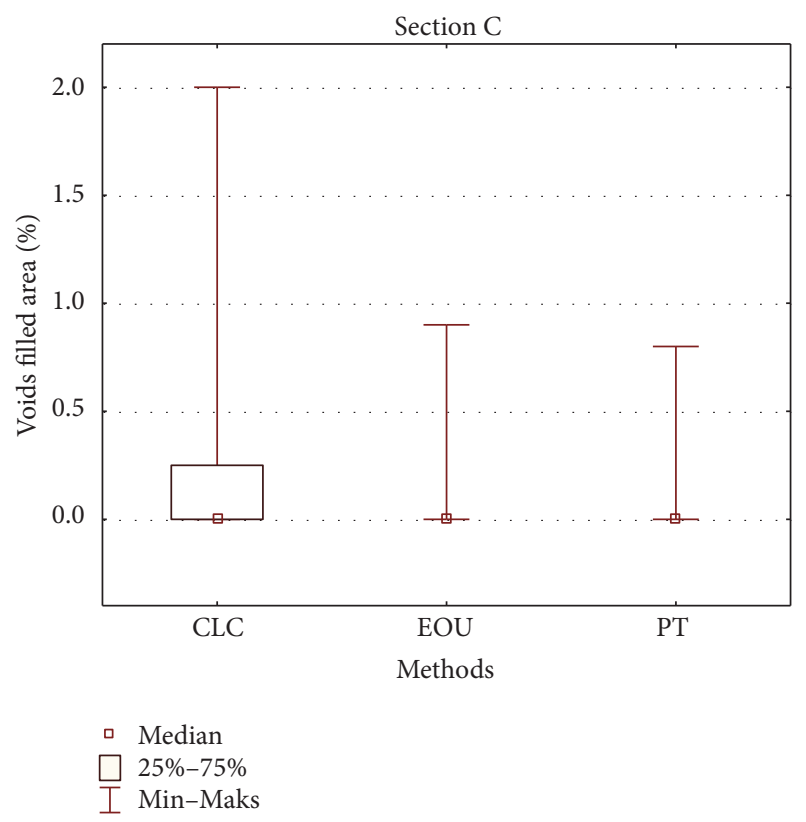

FIGURE 12: Box plots illustrating the median traces and minimal and maximal values of the voids in the filled area in each experimental group, section $\mathrm{C}$.

chemical properties of both the seal and the gutta-percha, leakage may occur both during and after tooth cavity obstruction, irrespective of the type of material used. Although empty spaces may be formed by the sealer shrinking during cold lateral condensation, this phenomenon may be limited by the use of materials known to have low sorption and dissolution coefficients. During filling with thermic methods, 
empty spaces are created as a result of the contraction of gutta-percha and sealer, among other things. It is important to note that this reduction in volume affects both the alpha and beta forms of gutta-percha. Meyer et al. [17] note that gutta-percha contracts by around 7\% while cooling from $90^{\circ} \mathrm{C}$ to $35^{\circ} \mathrm{C}$ (gutta-percha alpha, $7.2 \%$; gutta-percha, beta$7.3 \%)$ Lee et al. [18] report less contraction of gutta-percha during injection techniques (Ultrafil, 2.2\% contraction) than thermal application of gutta-percha with a plasticized obturator (Thermafil, 3.5\% shrinkage). The authors of the study attribute these larger changes in volume observed using the Thermafil technique to the slight differences in the chemical compositions of different thermal gutta-percha root canal obturation systems [18]. A Japanese study suggests that conventional lateral condensation may be more suitable than the application of melted gutta-percha because it does not undergo a large degree of shrinkage while setting [19]. They also note that temperature changes associated with the thermal method of tooth cavity obturation not only speed up the polymerisation of the sealers but also result in reduced mass or volume. The greatest mean loss of mass was observed for RSA ${ }^{\circledR}$ and Epiphany ${ }^{\circledR}$ sealer, and the least for AH Plus sealer [20]. It is important to note that, in the case of application of epoxy-based sealer, its mass fell by as much as $22.74 \%$ compared to baseline. Other studies show that temperature rise has a negligible impact on such $\mathrm{AH}$ Plus ${ }^{\circledR}$ properties such as viscosity, fluidity, and adhesion to the dentin $[21,22]$. In the present study, the lower percentage of voids was detected in the canals filled with thermal methods as compared to canals obturated by cold lateral condensation. It should be however emphasized that the differences between particular fillings were found to be statistically insignificant. It is interesting to note that there was a relatively small canal area which was not filled by either gutta-percha or sealer. Similarly, De-Deus et al. [12] observed a comparable amount of voids in the periapical portion of the canal after using the thermoplasticized obturator and cold lateral condensation. The mean percentage area occupied by voids was $0 \%-0.05 \%$ after using Thermafil and $0.07 \%-0.2 \%$ after cold lateral condensation. Other investigations did not demonstrate any statistically significant difference in the percentage distribution of voids in the canals filled by cold lateral condensation, by the thermal method with a thermoplasticized obturator (Thermafil), or by warm vertical compaction (System B). Comparable distributions and size were noted for the voids in canals filled by continuous wave and cold lateral condensation $[5,23]$. Other reports reveal statistically significant differences in the amount and size of voids within fillings created with warm and cold gutta-percha. Gençoglu et al. [9] and Weis et al. [10] report significantly more voids in canals filled with cold lateral and warm vertical condensation than in fillings performed with the Thermafil system. ElAyouti et al. [24] report that voids occupied a significantly larger area in the periapical portion of a canal after the application of Thermafil than after warm vertical condensation. A scanning electron microscope analysis by Grga et al. [25] revealed the presence of voids between the root canal wall and the filling material, as well as between the plastic obturator core and gutta-percha, in fillings performed with Thermafil.
Two possible factors influencing the observed differences in the percentage of voids in filled areas are the degree of experience of the operator and any variation in the methods of root canal obturation. In addition, the type of microscope and magnification used during the inspection of root cross sections and the method of specimen preparation can also influence the outcome, despite the same methods being used to fill the root canal. To prepare a microscope sample, the roots are first cut or split. Next, for examination by metallographic microscopy, their surfaces are polished in a grinding and polishing machine with abrasive papers of decreasing grit size. However, for analysis in an electron microscope, the samples are deposited with gold and coal alloys in a vacuum. Thus, the preparation phase of the research material may contribute to the formation of new voids or the obliteration of existing ones within the root canal filling.

\section{Conclusion}

In round canals, thermal methods of root canal obturation allow higher PGFA values to be obtained than by cold lateral condensation, but the content of voids is comparable. The combination of a metallographic microscope (Nicon Eclipse MA 200) and Nis Elements software is an effective method for evaluating root canal fillings and endodontic materials.

\section{Competing Interests}

The authors declare that they have no competing interests.

\section{Acknowledgments}

The authors acknowledge financial sources 502-03/2-04402/502-24-057.

\section{References}

[1] J. Whitworth, "Methods of filling root canals: principles and practices," Endodontic Topics, vol. 12, no. 1, pp. 2-24, 2005.

[2] J. F. Siqueira Jr., "Aetiology of root canal treatment failure: why well-treated teeth can fail," International Endodontic Journal, vol. 34, no. 1, pp. 1-10, 2001.

[3] L. B. Peters, P. R. Wesselink, and W. R. Moorer, "Penetration of bacteria in bovine root dentine in vitro," International Endodontic Journal, vol. 33, no. 1, pp. 28-36, 2000.

[4] T. Tasdemir, C. Yesilyurt, K. T. Ceyhanli, D. Celik, and K. Er, "Evaluation of apical filling after root canal filling by 2 different techniques," Journal of the Canadian Dental Association, vol. 75, no. 3, p. 201, 2009.

[5] G. De-Deus, C. Reis, D. Beznos, A. M. G. de Abranches, T. Coutinho-Filho, and S. Paciornik, "Limited ability of three commonly used thermoplasticized gutta-percha techniques in filling oval-shaped canals," Journal of Endodontics, vol. 34, no. 11, pp. 1401-1405, 2008.

[6] M.-K. Wu, A. Kašt'áková, and P. R. Wesselink, "Quality of cold and warm gutta-percha fillings in oval canals in mandibular premolars," International Endodontic Journal, vol. 34, no. 6, pp. 485-491, 2001. 
[7] M.-K. Wu, L. W. M. Van Der Sluis, C. N. Ardila, and P. R. Wesselink, "Fluid movement along the coronal two-thirds of root fillings placed by three different gutta-percha techniques," International Endodontic Journal, vol. 36, no. 8, pp. 533-540, 2003.

[8] G. De-Deus, E. D. Gurgel-Filho, K. M. Magalhães, and T. Coutinho-Filho, "A laboratory analysis of gutta-percha-filled area obtained using Thermafil, system B and lateral condensation," International Endodontic Journal, vol. 39, no. 5, pp. 378383, 2006.

[9] N. Gençoglu, Y. Garip, M. Baş, and S. Samani, "Comparison of different gutta-percha root filling techniques: thermafil, QuickFill, System B, and lateral condensation," Oral Surgery, Oral Medicine, Oral Pathology, Oral Radiology, and Endodontics, vol. 93, no. 3, pp. 333-336, 2002.

[10] M. V. Weis, P. Parashos, and H. H. Messer, "Effect of obturation technique on sealer cement thickness and dentinal tubule penetration," International Endodontic Journal, vol. 37, no. 10, pp. 653-663, 2004.

[11] J. Wolcott, T. Van Himel, W. Powell, and J. Penney, "Effect of two obturation techniques on the filling of lateral canals and the main canal," Journal of Endodontics, vol. 23, no. 10, pp. 632-635, 1997.

[12] G. De-Deus, C. M. Maniglia-Ferreira, E. D. Gurgel-Filho, S. Paciornik, A. C. R. Machado, and T. Coutinho-Filho, "Comparison of the percentage of gutta-percha-filled area obtained by Thermafil and System B," Australian Endodontic Journal, vol. 33, no. 2, pp. 55-61, 2007.

[13] I. S. Jarrett, D. Marx, D. Covey, M. Karmazin, M. Lavin, and T. Gound, "Percentage of canals filled in apical cross sectionsan in vitro study of seven obturation techniques," International Endodontic Journal, vol. 37, no. 6, pp. 392-398, 2004.

[14] B. R. Prashanth and S. Vasundhara, "Analysis of percentage of gutta-percha filled area using single cone, continuous wave of compaction, Thermafil and Obtura II in 0,06 taper prepared root canals," Endodontolgy, vol. 21, no. 2, pp. 22-28, 2009.

[15] P. R. Cathro and R. M. Love, "Comparison of MicroSeal and System B/Obtura II obturation techniques," International Endodontic Journal, vol. 36, no. 12, pp. 876-882, 2003.

[16] K. Gulsahi, Z. C. Cehreli, T. Kuraner, and F. T. Dagli, "Sealer area associated with cold lateral condensation of gutta-percha and warm coated carrier filling systems in canals prepared with various rotary NiTi systems," International Endodontic Journal, vol. 40, no. 4, pp. 275-281, 2007.

[17] K. M. Meyer, F. Kollmar, J. F. Schirrmeister, F. Schneider, and E. Hellwig, "Analysis of shrinkage of different gutta-percha types using optical measurement methods," Schweizer Monatsschrift für Zahnmedizin, vol. 116, no. 4, pp. 356-361, 2006.

[18] C. Q. Lee, Y. Chang, C. M. Cobb, S. Robinson, and E. M. Hellmuth, "Dimensional stability of thermosensitive guttapercha," Journal of Endodontics, vol. 23, no. 9, pp. 579-582, 1997.

[19] G. Tsukada, T. Tanaka, M. Torii, and K. Inoue, "Shear modulus and thermal properties of gutta percha for root canal filling," Journal of Oral Rehabilitation, vol. 31, no. 11, pp. 1139-1144, 2004.

[20] A. Kierklo, M. Pawińska, and J. Siudyn, "Evaluation of the quality of root-canal obturation in its adaptation and sealing aspects-based on SEM microscope images," Journal of Stomatology, vol. 63, no. 3, pp. 139-147, 2010.

[21] S. Lacey, T. R. Pitt Ford, X.-F. Yuan, M. Sherriff, and T. Watson, "The effect of temperature on viscosity of root canal sealers," International Endodontic Journal, vol. 39, no. 11, pp. 860-866, 2006.
[22] P. Beltes, P. Keki, K. Kodonas, C. Gogos, and N. Economides, "Effect of heat application on adhesion of epoxy resin sealer," Journal of Endodontics, vol. 34, no. 11, pp. 1378-1380, 2008.

[23] A. D. Keçeci, G. Ünal, and B. H. Şen, "Comparison of cold lateral compaction and continuous wave of obturation techniques following manual or rotary instrumentation," International Endodontic Journal, vol. 38, no. 6, pp. 381-388, 2005.

[24] A. ElAyouti, P. Kiefner, H. Hecker, A. Chu, C. Löst, and R. Weiger, "Homogeneity and adaptation of endodontic fillings in root canals with enlarged apical preparation," Oral Surgery, Oral Medicine, Oral Pathology, Oral Radiology and Endodontology, vol. 108, no. 3, pp. el41-e146, 2009.

[25] D. Grga, V. Miltenić, and M. Jelić, "SEM study of Thermafilobturation technique with 5 endodontic sealers," Balkan Journal of Stomatology, vol. 11, no. 2, pp. 123-128, 2007. 

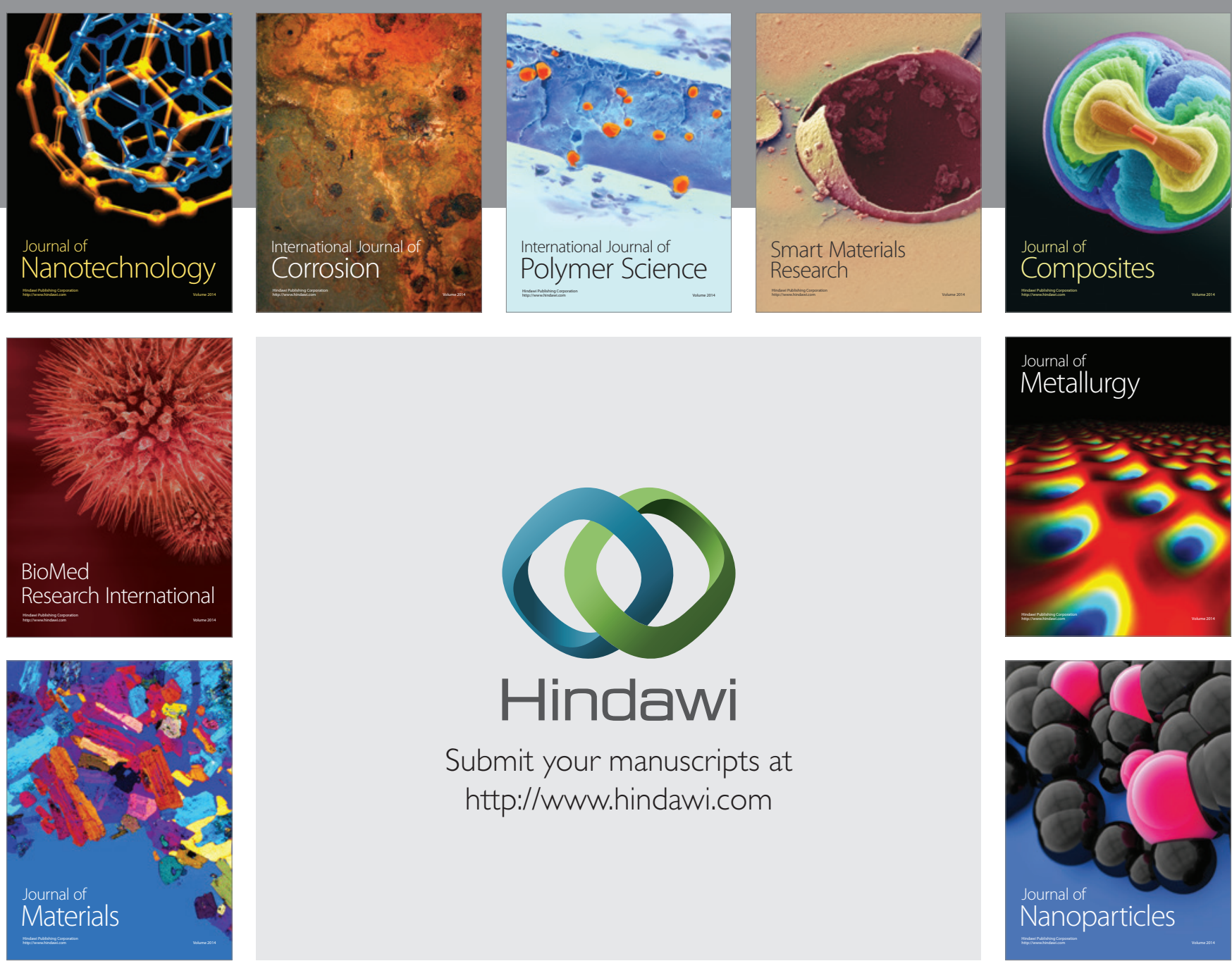

\section{Hindawi}

Submit your manuscripts at

http://www.hindawi.com

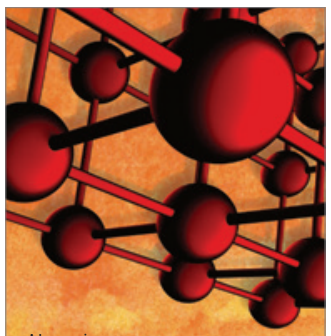

Materials Science and Engineering
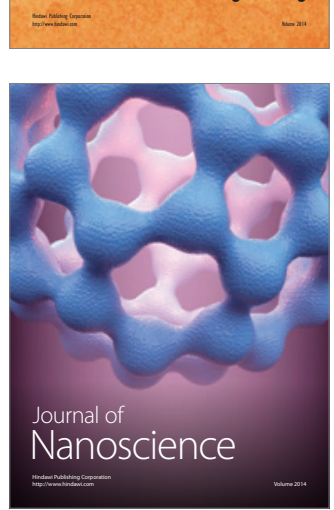
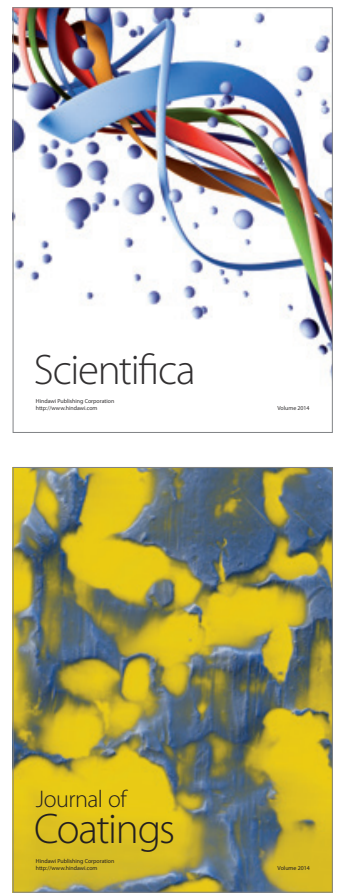
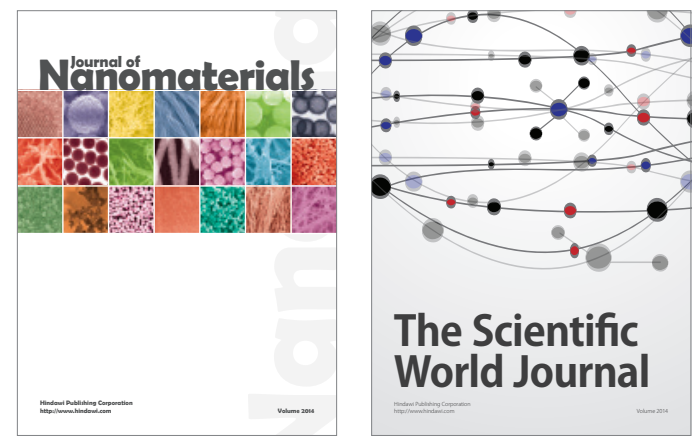

The Scientific World Journal
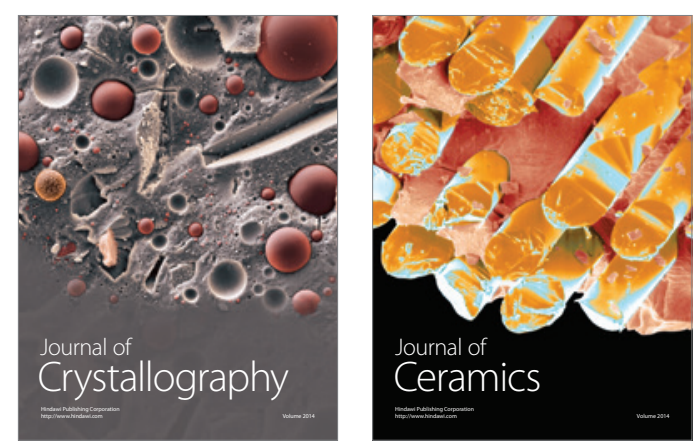
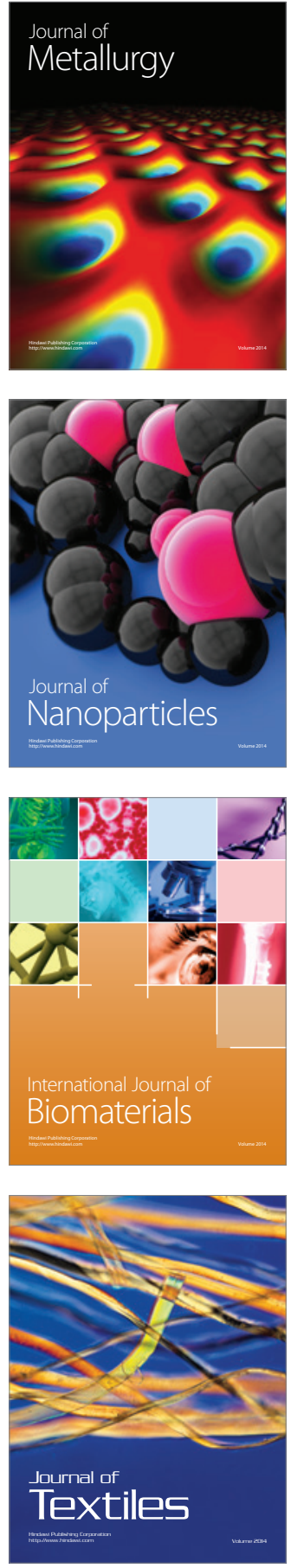